\section{Soehendra stent retriever - a useful device for pancreatic pseudocyst drainage}
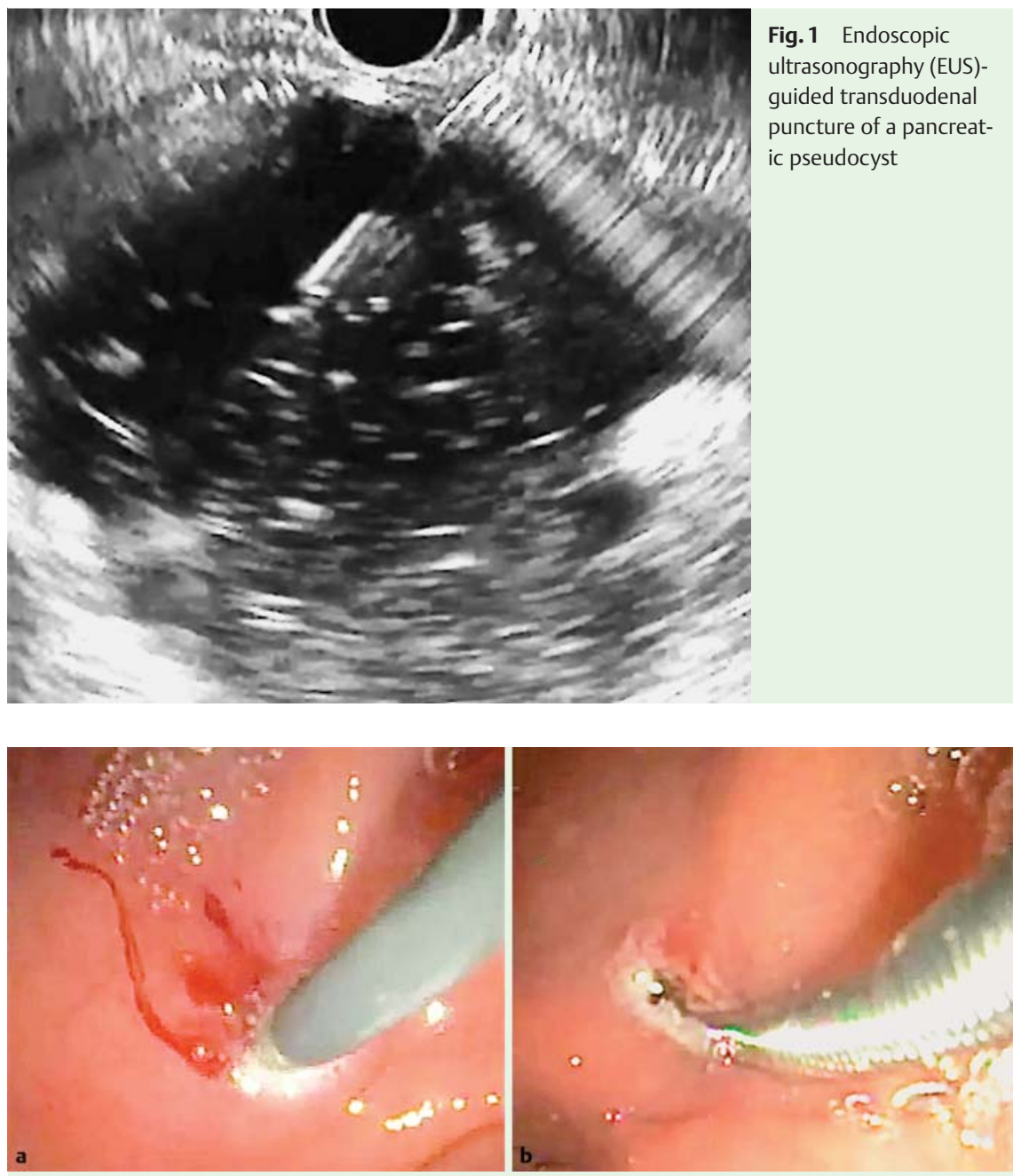

Fig. 2 Endoscopic images showing: a an attempt being made to enter the cyst using a cystotome but the wall was too hard and thick; $\mathbf{b}$ a Soehendra stent retriever being introduced with clockwise rotational movements.

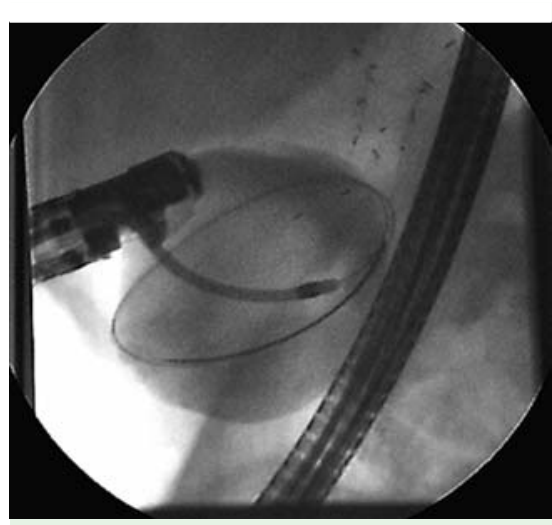

Fig. 3 Radiographic image of the Soehendra stent retriever, with which we were able to gain access to the pseudocyst.
A 52-year-old patient with chronic pancreatitis was admitted for drainage of two symptomatic pancreatic pseudocysts. Endoscopic ultrasonography (EUS) showed pseudocysts in the pancreatic body and head of $50 \times 40 \mathrm{~mm}$ and $30 \times 20 \mathrm{~mm}$ in size, respectively.

We first performed transgastric drainage of the pancreatic body pseudocyst, using a lumen-apposing stent. In the same session, we approached the pancreatic head pseudocyst. A transduodenal puncture of the cyst was made with a 19-gauge needle ( $\bullet$ Fig. 1 ). A cystotome was used, but it failed to get through the hard and thick cystic wall ( Fig.2a). A through-

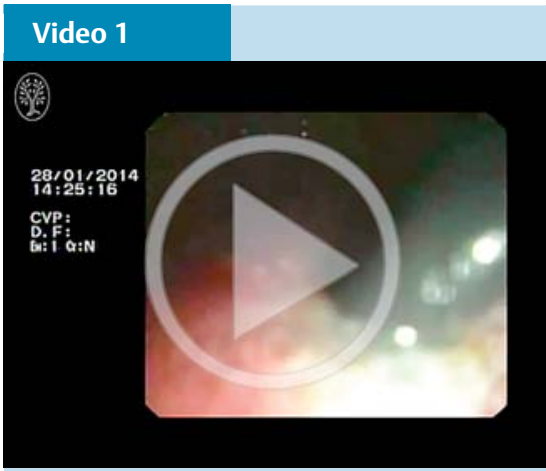

A transduodenal puncture of the pancreatic head pseudocyst was made with a 19-gauge needle. Contrast was injected and a guidewire was inserted. Repeated attempts to access the cyst were unsuccessful using a 6-Fr cystotome and through-the-scope balloon dilation owing to its hard and thick wall. A 10- $\mathrm{Fr}$ Soehendra stent retriever was successfully introduced through the scope over the guidewire, using clockwise rotational movements while pushing the device into the cavity. An outpouring of the contents of the cyst into the duodenum was seen and a double-pigtail stent ( $8.5 \mathrm{Fr}$ ) was then inserted to drain the pseudocyst.

the-scope balloon dilation was attempted, but without success. A 10-Fr Soehendra stent retriever (SSR) was then introduced through the scope over the guidewire ( $\bullet$ Fig.2b). As when it is used for difficult biliary stenoses [1,2], we performed clockwise rotational movements while pushing the device into the cavity ( Fig.3). This maneuver finally allowed access to the pseudocyst, which was confirmed by outpouring of the contents of the cyst into the duodenum ( $\bullet$ Fig.4a). A double-pigtail stent $(8.5 \mathrm{Fr}, 4 \mathrm{~cm})$ was inserted ( $\bullet$ Fig. 4 b; $\bullet$ Video 1), allowing efficient drainage.

The authors present this case to demonstrate the usefulness of the SSR, extending its utility, not only in difficult biliary stenosis but also as a device that may allow access into pancreatic pseudocysts with a hard and thick wall.

Endoscopy_UCTN_Code_TTT_1AR_2AI

\section{Competing interests: None}



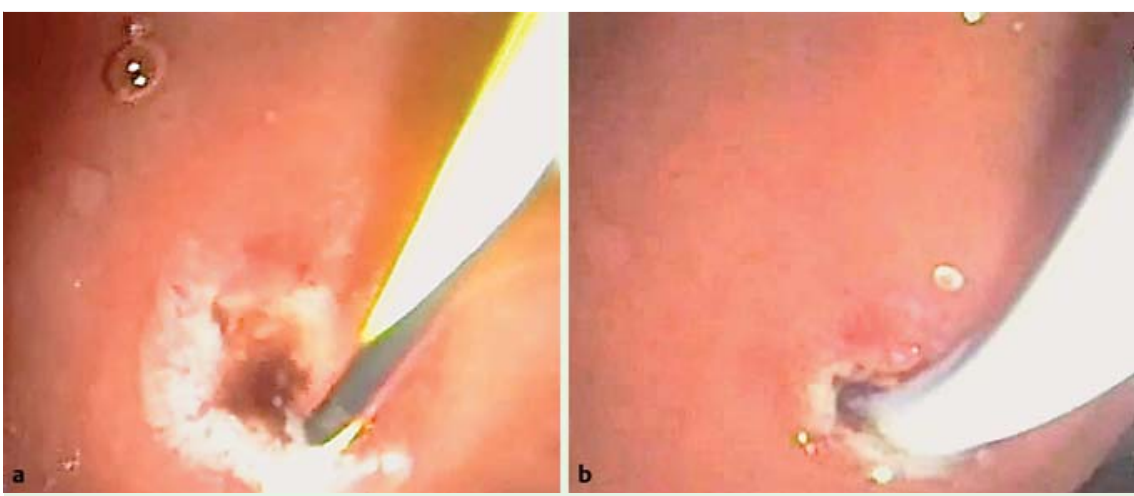

Fig.4 Endoscopic images showing: a the content of the cyst draining into the duodenum after the pseudocyst had been accessed; $\mathbf{b}$ a double-pigtail stent that was inserted for pseudocyst drainage.
Bibliography

DOI http://dx.doi.org/

$10.1055 / \mathrm{s}-0042-102880$

Endoscopy 2016; 48: E101-E102

(c) Georg Thieme Verlag KG

Stuttgart · New York

ISSN 0013-726X

\section{Corresponding author}

\section{Vera Costa Santos, MD}

Rua Professor Alfredo Bensaude $n^{\circ} 10,1^{\circ}$ direito

9500-700, Ponta Delgada

Portugal

vera@multi.pt

veracostsantos@gmail.com

\section{Vera Costa Santos, Nuno Nunes, Filipa Ávila, Paulo Massinha, Ana Catarina Rego, José Renato Pereira, Nuno Paz, Maria Antónia Duarte}

Department of Medicine, Hospital do Divino Espírito Santo de Ponta Delgada, Ponta Delgada, Portugal

\section{References}

1 Tsutsumi K, Kato H, Sakakihara I et al. Dilation of a severe bilioenteric or pancreatoenteric anastomotic stricture using a Soehendra Stent Retriever. World J Gastrointest Endosc 2013; 5: 412-416

2 Kato H, Kawamoto H, Noma Yet al. Dilatation by Soehendra stent retriever is feasible and effective in multiple deployment of metallic stents to malignant hilar biliary strictures. Hepatogastroenterology 2013; 60: $286-$ 290 